\title{
Comparison of Integrated Assessment Models: Carbon Price Impacts on U.S. Energy
}

\author{
Jordan T. Wilkerson $^{\mathrm{a}^{*}}$, Benjamin D. Leibowicz ${ }^{\mathrm{a}}$, Delavane D. Turner ${ }^{\mathrm{a}}$, John P. Weyant $^{\mathrm{a}}$ \\ ${ }^{a}$ Management Science and Engineering Department, School of Engineering, Stanford University, \\ Stanford CA 94305 \\ ${ }^{*}$ Corresponding author, Tel.: +1 4153365831, E-mail address: Jordan.Wilkerson@ gmail.com
}

\begin{abstract}
Integrated assessment models (IAMs) are increasingly used to evaluate carbon policy impacts on energy structure, but different models can yield considerably different results. This paper seeks to frame model results for policymakers and other consumers of model outputs. In this analysis we compare three models: GCAM, MERGE, and EPPA. We apply diagnostic carbon price scenarios, such as ramps and shocks, to identify key differences in model behavior that drive inter-model variability in projected policy impacts on the U.S. energy system. We report model results using several economic parameterizations and find that variation in carbon emissions across models results primarily from differences in carbon intensity of energy supply. These differences arise because models include different low-carbon energy technology options and vary widely in how flexible the electricity supply sector is at adapting to a change in policy. The timing of emissions abatement is also strongly influenced by whether the model is a simulation or an inter-temporal optimization scheme and the amount of foresight exhibited in the model. Our analysis demonstrates the usefulness of novel IAM diagnostic indicators and clarifies model features that are highly relevant for consumers of model results.
\end{abstract}

Keywords: integrated assessment; model comparison; energy policy analysis

(C) 2014. This manuscript version is made available under the Elsevier user license http://www.elsevier.com/open-access/userlicense/1.0/ 


\section{Introduction}

Energy and climate models are essential tools for projecting potential economic and environmental impacts of a wide range of policy designs. Integrated assessment models (IAMs) capture macroeconomic interactions among global regions and link concepts and information from multiple disciplines of the natural and social sciences in a quantitative framework. This framework represents the energy economics of each region, integrated with a climate module. These are not simple, reduced-form, cost-benefit IAMs, but complex coupled systems with detailed process descriptions. The intent of such a model is to inform technology and economic policy decisions in light of climate impacts. Due to the general ease of use, run times measured in minutes, and inclusion of climate feedback, IAMs are moving quickly from research tools to providing policy recommendations (e.g., Nakicenovic et al., 2000; e.g., IWG, 2010).

While IAMs provide planners and policymakers with economic insights about potential impacts from climate and energy policies, these insights are often considered illusory. Pindyck (2013) concludes that IAMs have such crucial flaws that they are almost useless as tools for policy analysis, and that IAMbased analyses of climate and energy policies create a perception of knowledge and precision which is misleading at best. Differences between models are driven by assumptions and inputs. What is considered a reasonable assumption in a given model is a reflection of the modeler's perspective. Even if the inputs can be agreed upon, Stern (2013) claims that these models have more omissions than real effects, and focus mostly on tractable options instead of on the impacts of climate change on lives and livelihoods. These impacts are typically local, but not well connected to climate factors which operate at a global level; yet, the resolution of such models is not sufficient to even attempt to capture these effects.

Scientists are aware of these issues and are actively working to address them. The Stanford Energy Modeling Forum (EMF), for example, organizes research and diagnostic projects to compare models and improve the community's understanding of model behavior. Each EMF project addresses specific policyrelevant questions which allow the participating modelers the opportunity to improve their models in that IAM Comparison -1 
field. Some recent examples: EMF29 assessed the role of border carbon adjustments in unilateral climate policy (Böhringer et al., 2012); EMF28 compared scenarios for transforming the European energy system (Weyant et al., 2013); EMF24 compared climate policy and technology scenarios for the U.S. (Fawcett et al., 2014); and EMF27 evaluated interactions between climate change policy architectures and advanced energy technology availabilities at global scale (Weyant and Kriegler, 2014). Each of these studies included more than a dozen models and organizations.

The Assessment of Climate Change Mitigation Pathways and Evaluation of the Robustness of Mitigation Cost Estimates (AMPERE) project included 22 institutions and 17 models (Kriegler, Riahi, et al., 2014). This three-year study assessed the potential costs of delaying climate policy, technology availability and path dependency of energy systems, and the implications of action in a fragmented international policy landscape. Others have addressed a wide range of timely topics (e.g., EMF, 2004; Weyant et al., 2006, 2013; Clarke et al., 2009; Fawcett et al., 2009).

Large inter-model comparisons, such as EMF and AMPERE, typically harmonize the models by setting, at a minimum, the values of population and GDP to be similar (e.g., EMF, 2011; Kriegler, 2013). Depending on the focus of the study, other parameters can also be harmonized. This allows different models and methods to be more easily compared. Such model comparison efforts have made model behaviors and features more accessible to the community at large.

These inter-model comparison studies are very useful for comparing model responses, but the models and scenarios generally remain under the control of the modelers. Some organizations have made the executable code available to the general public through user groups (e.g., GCAM). IAMs will increasingly be accessible to anyone. This will put the responsibility of properly configuring the model and interpreting the results squarely in the hands of the potentially naive user.

IAMs come in all different shapes and sizes without a formal nomenclature, although there have been attempts to classify them. Schneider (1997) proposed a hierarchy for IAMs, roughly paralleling IAM Comparison - 2 
model development as IAMs incorporate more components which reflect "real world" impacts and policy responses - in other words, as they move from multidisciplinary to inter-disciplinary coupling of physical, biological, and social scientific disciplines. This hierarchy was revisited several years later (Schneider and Lane, 2005). Goodess et al. (2003) described the taxonomy of more than a dozen IAMs with respect to baseline climatology reference data, simple climate model, calculated climate change variables, and the treatment of uncertainty. Stanton et al. (2009) reviewed 30 IAMs in four key areas: the connection between model structure and the type of results produced; uncertainty in climate outcomes and projection of future damages; equity across time and space; and abatement costs and the endogeneity of technological change. The authors found that differences in how these issues are treated can substantially affect model results and their implied policy prescriptions.

The executable codes for some IAMs can already be accessed by the general community. As more models become available, modelers will need to be more transparent about code structure and assumptions. Equally as important, model users will need to perform due diligence before selecting a model (or models) to use. There are dozens of IAMs to choose from when evaluating policy options and each has different strengths and weaknesses, solves using different techniques, and has different levels of technological and regional aggregation. So it is critical that consumers of model results (e.g., scientists, policy makers, leaders in emerging technologies) know how a particular model behaves (and why) before making decisions based on the results.

This paper illustrates the importance of understanding the model framework and assumptions. We do this by showing that the implications of a global carbon tax on the U.S. energy system depend on the particular IAM used. This paper is organized as follows: Section 2 introduces the models for this comparison and outlines our approach and methods. We describe our results in Section 3 and discuss our most important findings in Section 4. We conclude in Section 5 with policy and modeling implications.

IAM Comparison - 3 


\section{Methods}

\subsection{Models in this study}

We run three models: GCAM, MERGE, and EPPA. All are all well-established IAMs, but are significantly different from one another. All have a global scope but varying regional aggregation. GCAM emphasizes energy and land use, MERGE emphasizes investment and economic growth, and EPPA emphasizes the energy sector and its interactions with the broader economy. GCAM and EPPA are recursive dynamic simulation models, but MERGE is an inter-temporal optimization model. MERGE and EPPA are general equilibrium models, while GCAM is a partial equilibrium model. These and other differences are summarized in Table 1. Each model also has different input and output parameters and formats, and each has a unique set of initial conditions, computational time step, and run duration, which increase the level of complexity for direct comparisons.

\section{Table 1) Model comparison summary.}

\subsubsection{Global Change Assessment Model (GCAM)}

GCAM, first laid out by Edmonds and Reilly (1986), is a global model with 15 regions. Each region is parameterized with region-level data and the model provides region-specific output. The model has three major components or submodules: core energy, agriculture and land-use (AgLU), and Model for Assessment of Greenhouse-gas Induced Climate Change (MAGICC), making GCAM a full IAM. GCAM is a partial equilibrium economic model that solves for prices to equilibrate supply and demand in certain markets at each time step. The core energy submodule includes all primary, intermediate, and end-use energy markets, as well as greenhouse-gas (GHG) markets if a cap-and-trade mitigation policy is enabled. AgLU solves for equilibria in agriculture and forestry markets, allowing for an examination of land-use change emissions. AgLU is linked to the core energy market through biomass energy crops. MAGICC is

IAM Comparison -4 
a reduced-form climate model that takes global emissions as an input and produces global temperature and sea level rise as outputs (Wigley, 2008).

Prices in GCAM are set such that supply equals demand, but the model combines this top-down macroeconomic core with considerable bottom-up technology detail. Technology change is modeled in a simple fashion, using an autonomous energy efficiency improvement (AEEI) parameter that improves the energy efficiency of the economy over time and technological improvement parameters on each new technology that lower the cost of production over time. Each of these parameters is exogenously defined.

We use GCAM version 3.1 release r4509, which has 5-year time steps from 1990 to 2095. GCAM is a simulation model, but does contain a subroutine to determine the optimal time path of carbon prices in order to minimize the present discounted value of costs. This allows GCAM to solve for the least-cost path to meet a specified global atmospheric $\mathrm{CO}_{2}$ concentration target. For further detail on the model, please see Edmonds et al. (1997) and Kim et al. (2006).

\subsubsection{Model for Evaluating Regional and Global Effects of GHG Reduction Policies (MERGE)}

MERGE is a general equilibrium model with inter-temporal optimization that combines top-down representation of the global economy with bottom-up characterization of the energy supply sector. The model captures macroeconomic interactions using a nested production function that depends upon the inputs of capital and labor, as well as electric and non-electric energy. The model also includes a reducedform representation of the climate system. The objective of MERGE is to maximize the present value of utility from consumption. Savings and investment decisions are modeled so that each region maximizes the net present value of utility from consumption. The model's objective function is a weighted sum of each region's discounted utility where weights are determined using an iterative Negishi process. MERGE features nine regions of the world, although regions can be flexibly defined, as the model is parameterized with country-level socioeconomic data that can be aggregated accordingly.

IAM Comparison - 5 
The model covers 1990 to 2100 with ten-year time steps (with climate impacts projected through 2200). The model has perfect foresight and begins immediately to accommodate for a future binding environmental constraint to maximize utility over all model years. One of MERGE's strengths as a general equilibrium model is that the bottom-up representation of the energy supply sector allows it to choose among specific options to generate electricity and produce non-electric energy. MERGE uses an AEEI parameter, which improves energy efficiency of the economy over time, and technological improvement parameters on each new technology that lower the cost of production over time. These parameters are exogenously defined, as are the constraints limiting the diffusion of new technologies. MERGE's predecessors are ETA-MACRO and Global 2100. For more detail on the model, please see Manne and Richels (1992) and Manne et al. (1995). We use MERGE version 7, as specified for the EMF27 scenarios (Blanford et al., 2013).

\subsubsection{Emissions Prediction and Policy Analysis (EPPA) Model}

Developed and maintained by the MIT Joint Program on the Science and Policy of Global Change, the EPPA model is a multi-regional, general equilibrium model of the world economy (Paltsev et al., 2005). Used by itself, EPPA is an energy-economic model that lacks the climate submodule required to be a true IAM. However, it can be used as one component of the larger Integrated Global System Modeling (IGSM) framework, which includes linkages with a coupled ocean, atmosphere, and land earth system model. EPPA has a time horizon of 2100 in 5-year time steps. Economic base-year data (1997) is obtained from Purdue University's Global Trade Analysis Project (GTAP) database (Dimaranan and McDougall, 2002). We use EPPA 4.1.

Production sectors span the entire economy but particular attention is devoted to energy resources, electricity, and agriculture. Each region has a household sector represented by a single utility-maximizing consumer and production sectors represented by a single profit-maximizing firm. All production and utility functions are described by a nested constant elasticity of substitution structure. This nest structure allows fundamental factors and inputs to be combined to form goods used as intermediate inputs to IAM Comparison -6 
higher-level production functions, ultimately resulting in the production of final goods and services. Elasticities of substitution are defined separately at each level of the nest, enabling considerable flexibility in defining utility functions and production processes.

Prices in EPPA are endogenous to enforce general equilibrium. This requires that all economic agents in all markets have income equal to the value of endowments (plus tax revenue for governments). All markets will have an exact balance between supply and demand. Inter-regional trade is represented for all commodities and goods.

For a macroeconomic model, EPPA contains a fair degree of technological detail. It represents conventional energy resources and electricity technologies as well as a handful of advanced supply technologies such as natural gas combined cycle, fossil fuels with carbon capture and sequestration (CCS), biofuels, and advanced nuclear. Advanced technologies become available in future periods and their penetration is constrained endogenously via an initially scarce fixed-factor input that represents technology-specific expertise and engineering capacity. Technology change occurs through an AEEI, improvements in the productivity of land and labor, price-induced input substitutions, and the introduction of advanced technologies.

\subsection{Approach}

Results from an individual model or single scenario should not be considered the 'right' answer, but rather a possible outcome based on a set of assumptions, calculations, and applied policies. By running a suite of scenarios, including some with extreme constraints, one can infer a range of possible outcomes from the model results. Perhaps more importantly, sensitivities to changes in certain variables can provide insight into complex interactions within the model. The resulting trends from successive scenarios are at least as useful as the physical answer and often provide more insight into economic and environmental responses (Huntington et al., 1982).

IAM Comparison - 7 


\subsubsection{Policy Scenarios}

For this study, we evaluate two types of carbon taxes ${ }^{1}$ : tax ramps that begin low then rise over time, and fixed carbon tax shocks that remain constant through the duration of the model run once the tax is introduced. We apply the explicit global carbon tax and evaluate the impacts to the U.S. region from each model. In each time period, the models evaluate costs and select an appropriate set of technologies to meet expected energy demands based on the individual model's algorithm and assumptions. We focus on the U.S. impacts since the models generally include more detail about the U.S. energy-economy than they do for some other regions. Also, this region represents a single geopolitical boundary, unlike most other regions which are aggregates of countries (see Table 2). It is important to note that in all three models, revenue from the carbon tax is redistributed to households in lump sum fashion. Since prior studies have shown that using this revenue to reduce the level of ordinary distortionary taxes can lead to more efficient outcomes (e.g., Goulder, 2013), this can be considered a common model limitation, a point raised by Fawcett et al. (2014).

Table 2) Regions in each model.

Ramp scenarios are $\$ 0 / \mathrm{tCO}_{2}$ in 2010 and begin in the first model year beyond the present. This is 2015 in GCAM and EPPA, and 2020 in MERGE. The tax amount escalates annually based on the respective profile, and reaches a maximum of $\$ 200 / \mathrm{tCO}_{2}$ in 2090. Setting ramps to converge at 2090 allows for a convenient comparison between models, since the final model year differs between models. A linear profile is represented when $\alpha=1$ and a quadratic profile when $\alpha=2$ in the following equation. The linear profile begins with an initial tax of $\$ 12.50 / \mathrm{tCO}_{2}$ in 2015 for GCAM and EPPA; however,

\footnotetext{
${ }^{1}$ There have been numerous studies evaluating the impacts and costs of carbon and GHG taxes. Most studies apply taxes to meet a set reduction in GHG emissions or atmospheric concentration (e.g., Manne and Richels, 1992; Nordhaus, 1992, 1993; Knopf et al., 2011; Bosetti et al., 2012). IAM Comparison -8
} 
MERGE operates in 10-year time steps, so the first tax year is 2020 at a value of $\$ 25 / \mathrm{tCO}_{2}$, which matches GCAM and EPPA in 2020.

$$
\operatorname{Tax}(t)=\$ 200 / \mathrm{tCO}_{2} *\left(\frac{t-2010}{2090-2010}\right)^{\alpha}
$$

The introduction of even a modest carbon tax ramp may prove politically infeasible. So, the carbon shocks consider the impact of significant carbon fees at future time periods when it becomes apparent that 'doing nothing' today was insufficient. We consider $\$ 200 / \mathrm{tCO}_{2}$ shocks that begin in future years: 2020 , 2050, and 2080. The purpose of considering these shocks is to determine the impact of large and sudden carbon taxes on emissions and the economy, and to provide a comparison of model results from a significant single period-single parameter model change. All tax profiles are depicted in Figure 1, where the values are shown in 2005 USD $(2005 \$) .^{2}$

Figure 1) Carbon tax profiles applied in all scenarios. Taxes are in $2005 \$$.

\subsubsection{Kaya Identity}

Beyond comparing overall policy impacts on carbon emissions, we isolate key economic drivers to illustrate how the policy affects structural changes and technology efficiency. One common starting point is the Kaya Identity (Kaya, 1990), which has been used, for example, to compare IPCC emissions scenarios. The Kaya identity disaggregates carbon emission in terms of its demographic, economic, and technological drivers. Carbon emissions (C) are related to the population (P), affluence or economic welfare (GDP/P), primary energy intensity (PE/GDP), and carbon intensity (C/PE).

\footnotetext{
2 Taxes in GCAM are entered in 1990\$, MERGE in 2000\$, and EPPA in 1997\$. Using the National Bureau of Economic Research NIPA tables (NBER, 2013) we deflate GCAM by 0.72262, MERGE by 0.88723, and EPPA by 0.84628 . So, a $\$ 200$ tax in 2005 will be equivalent to $\$ 144.52$ in 1990 (GCAM), \$177.45 in 2005 (MERGE), and $\$ 169.26$ in 1997 (EPPA). IAM Comparison - 9
} 
Population and GDP assumptions determine future levels of service demands and influence future prices, and are at the center of almost any analysis. Population is exogenous in all three models, but with different assumptions about growth. GDP is also exogenous in GCAM. Although GDP is endogenous in MERGE and EPPA, we will show that it does not vary much from the baseline in any scenario. In some major inter-model comparisons that involve the model developers, the participating models are harmonized by setting, at a minimum, the values of population and GDP to be similar (e.g., EMF, 2011; Kriegler et al., 2013). Here, we do not harmonize the models, but take these economic drivers as-is because the typical policy maker (or staff) would not conduct such an inter-model exercise and some quantities are endogenous in some models but not others.

Hummel and Weyant (2006) expanded the fundamental Kaya identity by decoupling final energy (FE) from PE to reveal the energy efficiency of economic activity (FE/GDP) and energy supply losses (PE/FE). In models which focus on technology representation, final energy is often the starting point in the energy consumption calculation (e.g., Wilkerson et al., 2013). However, in the current study, only GCAM explicitly includes end-use technologies and computes both PE and FE. The lack of these technologies is a characteristic of macroeconomic models and makes it difficult to assess the impacts of policies on consumers.

Since population is fixed and GDP is either exogenous or not heavily affected by model scenarios, and FE is not identified in all our models, the principal terms of interest for a Kaya analysis are those that affect changes in PE intensity or carbon intensity.

\subsubsection{IAM Diagnostics}

Kriegler, Petermann, et al. (2014) identified criteria that IAM diagnostic indicators should meet and offered four simple Kaya-like indicators which can characterize model behavior. These indicators

IAM Comparison - 10 
describe the size of the policy-induced emissions reduction, reliance on reducing carbon intensity (CI) versus energy intensity (EI), the scale of the energy system transformation, and mitigation costs as a function of carbon price. We apply the first three in this study. The fourth indicator, regarding mitigation costs, is not as useful here since we are interested in policy impacts on the structure of the energy sector, not on estimating the policy costs.

The first indicator, Relative Abatement Index (RAI), assesses the carbon reduction from the base case in a given year $(t)$. The RAI is simply the fraction of baseline emissions avoided in a given year.

$$
\operatorname{RAI}(t)=\frac{\mathrm{C}_{\text {base }}(\mathrm{t})-\mathrm{C}_{\text {policy }}(t)}{\mathrm{C}_{\text {base }}(\mathrm{t})}
$$

The second indicator, Carbon over Energy Intensity (CoEI), compares the fractions, or residuals (Res), of EI and CI between the policy case and the base scenario. This indicator identifies whether the dominant model response to a policy leverages more CI improvements $(\mathrm{CoEI}<1)$, leverages more EI improvements $(\mathrm{CoEI}>1)$, or is a balanced reduction of both $(\mathrm{CoEI} \approx 1)$.

$$
\operatorname{CoEI}(t)=\frac{\operatorname{Res}(C I(t))}{\operatorname{Res}(E I(t))}=\left(\frac{\mathrm{CI}_{\text {policy }}(t)}{\mathrm{CI}_{\text {base }}(t)} * \frac{\mathrm{EI}_{\text {base }}(t)}{\mathrm{EI}_{\text {policy }}(t)}\right)
$$

The third, Transformation Indicator (TI), quantifies the aggregate structural change in the electricity sector. This is effectively a measure of how different the energy supply mix in a given model year is from that of the reference year, where the relevant quantities are fractional shares of total energy. The change in fraction share of a given technology $\left(S_{i}\right)$ represents the 'distance' that technology, $i$, has transformed between a given year, $t$, and the base year, 2010. The sum of all technologies represents the total 'distance' or transformation between the base year and current year generation mix. Clarke et al. (2012) used a similar metric to compare generation mixes between regions. Each model includes a different set of electricity generation technologies, as shown in Table 3.

IAM Comparison - 11 


$$
\mathrm{TI}(t)=\sum_{i}\left|S_{i}(t)-S_{i}(2010)\right|
$$

Table 3) Electricity generation technologies in each model.

Combined, these three IAM indicators help clarify important model behaviors. The RAI reveals the magnitude of the carbon emissions response to a carbon price. The CoEI metric illustrates how heavily a model relies on reducing CI (i.e., using cleaner energy) versus reducing EI (i.e., using less energy). The TI specifies how quickly the energy structure adapts to an evolving policy.

\section{Results}

IAMs are simplified representations of regional economics and this family of models is best utilized for examining trends and not for determining absolute or optimal numbers. With this in mind, we review results relative to reference scenarios. However, some absolute results help highlight differences between the models, so we report those here as well.

\subsection{Population and GDP}

Figure 2a shows U.S. population assumptions for all three models. Population is exogenous to all three, but top-down per capita metrics are often the primary driver of regional and global energy consumption. The significant population spread among the models will impact other comparative statistics, such as GDP/person shown in Figure 2b. GDP is exogenous to GCAM, but endogenous to MERGE and EPPA. High and low GDP curves shown in Figure 2a span the full range from all our scenarios, showing that GDP is relatively insensitive to carbon price. EPPA and MERGE have similar values for GDP which grow about 20\% faster than the prescribed GCAM GDP. While population and GDP will not help diagnose differences between models, they are still important drivers of economic activity and emissions.

IAM Comparison - 12 
Figure 2) a) U.S. population and GDP; GDP is endogenous in MERGE and EPPA so the high and low lines establish the range from our scenarios; b) population and per capita GDP.

\subsection{Carbon Emissions}

The baseline carbon emissions for all three models are shown in Figure 3. GCAM predicts a steady rise in emissions to just over 2,100 million metric tons of carbon (MMtC) by 2090. The MERGE trajectory declines until 2040 before rising to nearly 3,000 MMtC by the end of the century. EPPA forecasts a large and consistent increase in emissions to almost 2,800 MMtC in 2075, then a drop in emissions over the final periods. At certain times the inter-model results vary by more than a third (e.g., EPPA vs. GCAM in 2080). MERGE and EPPA exhibit higher baseline emissions than GCAM by the end of the century, which can be partially attributed to their optimistic assumptions about the future of U.S. GDP. Even in the absence of a carbon policy, the models exhibit little agreement about future carbon emissions.

Figure 3) Carbon emissions: a) tax ramp scenarios; b) tax shock scenarios.

Actual energy-related carbon emissions in the U.S. was 1,536 MMtC in 2010 (EIA, 2012). GCAM and MERGE have higher 2010 emissions of 1,616 and 1,705 MMtC respectively, while EPPA starts with 1,365 MMtC in 2010. IAMs attempt to capture complex market structure and interactions with relatively simple calculations. As a result, they can often miss details such as this. This exemplifies that the most important results are the trends, not the absolute numbers.

All three models produce different baseline carbon emissions projections and widely varying predictions under carbon price scenarios. In several scenarios, GCAM and MERGE exhibit negative carbon emissions by the end of the model run due to significant deployment of bioenergy with CCS. EPPA, on the other hand, does not include this technology option, so negative emissions are infeasible.

IAM Comparison - 13 
CCS bioenergy is currently in its developmental phase, but choosing to represent this technology, or not, has clear implications for $\mathrm{CI}$ and emission forecasts.

The tax shocks in Figure $3 b$ illuminate important features of how the different models respond. With inter-temporal optimization and perfect foresight, MERGE anticipates future policy changes and begins preparing for a major shift in carbon price several decades before the policy is implemented. This activity reduces carbon emissions well in advance of the policy. From a planning perspective, a utility would prefer to not invest in a high-carbon-intensity power plant (with a useful life of 50 years) prior to the implementation of a major environmental policy which would make the new plant too expensive to operate. Although real economic agents could anticipate and plan for the possibility of a stringent carbon tax shock introduced suddenly in the relatively near future, optimization models with perfect foresight may be of little value for analyzing such long-range policies.

GCAM and EPPA, on the other hand, lack foresight, so tax shocks do not inspire any structural change until the financial incentive becomes active. Both models generate a very large drop in carbon emissions in the first period of the policy. GCAM is particularly flexible in adapting quickly to the new policy landscape, with emissions declining $82 \%$ in the first time step following the 2050 tax shock. The GCAM response includes many stranded assets and investment in new capacity, ${ }^{3}$ while the EPPA response features primarily a large reduction in energy use.

The shocks show the impact of a delay in implementing a carbon policy. For example, not implementing a linear tax ramp today will require a $\$ 200 / \mathrm{tCO}_{2}$ shock in 2050 just to catch up to annual emissions achieved from a linear ramp implemented today. That does not account for other critical climatological drivers, such as cumulative atmospheric $\mathrm{CO}_{2}$ concentration from the lack of action.

Figure 4) Relative Abatement Index (RAI) for the quadratic tax ramp and 2050 tax shock scenarios.

\footnotetext{
${ }^{3}$ This is problematic since this will undoubtedly affect GDP, yet GDP is exogenous in GCAM IAM Comparison - 14
} 
A more diagnostic method for comparing these results is through relative changes. RAI values for the quadratic tax ramp and 2050 tax shock are plotted in Figure 4. MERGE optimizes with perfect foresight and begins abating immediately. Its RAI rises steadily and is already 0.31 by 2040 , the period before the tax shock. So, before a carbon tax ever goes into effect, MERGE reduces emissions by $31 \%$ relative to the baseline. As simulation models, GCAM and EPPA both have an RAI of 0 until the tax shock is introduced in 2050. The difference in speed and magnitude of the response between the two models is striking. The GCAM RAI surges, in one time step, from 0 to 0.82 while EPPA rises only to 0.40. The magnitude of the immediate EPPA response is less than half that of GCAM. In fact, EPPA never reaches the 0.82 RAI attained by GCAM in just one period after the shock. The late decrease in RAI in EPPA for the 2050 shock is due to the depreciation of the current value of the constant carbon tax, which is also evident by the late increase in emissions in Figure $3 \mathrm{~b}$.

\subsection{Carbon Intensity}

The differences in CI are large. This is a major driver of differences in projected carbon emissions between models, beginning with large variations in the baseline (see Figure 5a). GCAM predicts that CI will remain steady at 17-18MMtC/EJ. In MERGE, CI rises at mid-century then stabilizes under 20MMtC/EJ. EPPA projects CI will increase to near GCAM levels until 2075 then return to where it started around $14 \mathrm{MMtC} / \mathrm{EJ}$. The strong influence of $\mathrm{CI}$ on emissions is more salient when comparing the shapes of the CI profiles in Figure 5 with the shapes of the emissions profiles in Figure 3.

Figure 5) Carbon intensity: a) tax ramp scenarios; b) tax shock scenarios.

Tax ramp responses begin with minor $\mathrm{CI}$ reductions which accelerate in the middle of the century. The potential to substitute low-carbon energy technologies in place of high-carbon conventional options improves over the first several decades but the tax isn't high enough to force early adoption of expensive IAM Comparison - 15 
technologies. However, under a sudden tax shock, the energy system is forced to adopt these costly lowcarbon technologies immediately. In the time step following a $\$ 200 / \mathrm{tCO}_{2}$ shock in $2020, \mathrm{CI}$ drops $60 \%$ below the baseline in GCAM and 30\% below the baseline in EPPA (see Figure 5b). With its perfect foresight and optimization structure, MERGE's CI profile deviates less from the baseline in response to a tax shock.

The difference in CI responses between GCAM and EPPA can be attributed to their energy supply technology options and how they constrain technology adoption. GCAM features a number of low-carbon technologies which are not included in EPPA, such as geothermal and bioenergy with CCS. GCAM's AgLU allows for rapid expansion of bioenergy crops, resulting in bioenergy carbon capture and even negative emissions (Wise et al., 2009). EPPA has a smaller set of low-carbon technologies. Their adoption in the early periods of availability is constrained by a mark-up factor that makes them more expensive than conventional alternatives and a scarce fixed-factor input representing knowledge and engineering capacity. Based on the response of CI to tax shocks, GCAM appears to have a more flexible energy system than EPPA.

\subsection{Primary Energy Intensity}

Compared to CI, primary EI is much less variable and Figure 6a shows there is already significant EI savings in the base case in all three models. The trajectory is similar across the models, falling steeply at first from $2-3 \mathrm{kWh} / \mathrm{GDP}$ then leveling out over time to $0.5-0.7 \mathrm{kWh} / \$ \mathrm{GDP}$ as opportunities to reduce EI are exhausted. The dramatic reduction in EI projected by the three models applies significant downward pressure on carbon emissions. Given how similar the primary EI profiles are across the models, differences in the EI of the economy are not an important source of inter-model variability in carbon emissions. One reason for this is that all three of these models use an exogenous AEEI. They cannot increase the rate of efficiency improvements for a given technology; they can only adopt more efficient IAM Comparison - 16 
technologies or reduce demand when faced with a price on carbon. Also, as a partial equilibrium model, GCAM cannot reduce energy demands and must rely on technology switching to supplement the AEEI.

Figure 6) Primary energy intensity: a) tax ramp scenarios; b) tax shock scenarios.

In the presence of a carbon policy, EI is improved below the baseline, but only by a small fraction. We observe that PE intensity declines toward a floor of about $0.5 \mathrm{kWh} / \$ \mathrm{GDP}$, which suggests that reducing energy consumption below this level necessarily implies a reduction in GDP for all three models. Applying a high carbon tax in the early periods (e.g., the 2020 shock) makes EI intensity fall steeply initially, but the path is simply more convex and approaches the same values as the other scenarios. Reducing EI is an important response to an aggressive carbon policy in the near future when PE intensity is still high and supply-side substitution possibilities are weak. EI reduction in MERGE is higher than in other models because it optimizes over the entire model horizon and determines that decarbonizing the energy system is more socially optimal than reducing energy consumption.

We can systematically compare CI to EI with the CoEI indicator. Figure 7 shows EPPA exhibits higher CoEI values than GCAM and MERGE, implying this model relies more on reducing EI for emissions abatement. With its limited set of low-carbon technologies and constraints on adoption, EPPA has a relatively rigid energy system. Opportunities to reduce CI are scarce and costly. Thus, CoEI $>1$ for EPPA since it reduces carbon emissions more from EI changes than from CI changes. GCAM and MERGE produce CoEI $<1$, implying that these models primarily leverage $\mathrm{CI}$ as a means for reducing emissions.

Figure 7) Carbon over Energy Intensity (CoEI) indicator for the quadratic tax ramp and 2050 tax shock scenarios.

The CoEI metric, in effect, is an indication of how conservative the technology choices available in each model are. If the model is optimistic about advanced technology adoption and has many options to IAM Comparison - 17 
choose from, the model will primarily leverage CI reductions. However, the metric lacks magnitude. For example, a model that shows a balanced reduction in CI and EI will have CoEI $\approx 1$. This result will be the same for a $50 \%$ or $5 \%$ reduction in both. While this provides a narrative for the model behavior, the lack of magnitude leaves the reader without an indication of significance.

Figure 8 illustrates how EI and CI evolve, or 'drift', under baseline and policy scenarios. This illuminates both the timing and the extent to which the models leverage EI and CI (this is different than the CoEI indicator which only indicates which one is leveraged more). The curves simultaneously represent the intensities (Figure 8a) or fractions (Figure 8b) of EI and CI relative to the reference year, 2010. ${ }^{4}$ The curves all start in the upper right in 2010 and generally move left (toward lower EI) and down (toward lower $\mathrm{CI}$ ). If the slope is 1 (equivalent to $\mathrm{CoEI} \approx 1$ ), then the two measures are reduced at the same rate. The benefit of this plot is to illustrate how CI and EI change relative to each other. For example, the baseline scenarios of each model already include significant reduction in EI but little (if any) reduction in CI. While the CoEI indicated the models tend to leverage reductions in CI more than EI under the policies, the drift plot shows that significant EI reductions are already accounted for in the baseline, leaving little room for additional improvement in EI under the policies.

Figure 8 also includes diamonds, squares, and triangles to indicate points on the curves when the carbon price reaches $\$ 50 / \mathrm{tCO}_{2}, \$ 100 / \mathrm{tCO}_{2}$, and $\$ 200 / \mathrm{tCO}_{2}$, respectively. Again, EI isn't materially affected by the different policy scenarios since the left-most points at the end of each scenario are only slightly lower in EI than the baseline scenario. However, as the carbon price exceeds $\$ 50 / \mathrm{tCO}_{2}, \mathrm{GCAM}$ and MERGE show increasing reduction in CI. EPPA, however, stands out among the models in that it relies exclusively on reducing EI until the carbon price is $\$ 100 / \mathrm{tCO} 2$, when the model suddenly shifts to rely almost exclusively on reducing CI.

\footnotetext{
${ }^{4}$ Others have shown similar comparisons by comparatively plotting percent reductions rather than intensities or fractions of intensities (e.g., Fig.1 of Krey et al., 2013). IAM Comparison - 18
} 
Figure 8) Drift plots showing evolving energy intensity and carbon intensity: a) intensities and b) indexed to 2010 value for each model. All models begin in the top right of the plots, then generally move left and down toward lower energy and carbon intensities through the model runs.

\subsection{Electricity Sector}

The results have shown that a large portion of inter-model variability in carbon emissions is attributed to differences in CI across models. CI is determined by the mix of technologies utilized in the energy sector. The electricity sector is the most technologically flexible component of the energy supply system (Wilkerson, 2014), so changes in the mix of technologies used to produce electricity largely dictate changes in $\mathrm{CI}$.

The electricity generation portfolios of the three models evolve somewhat similarly in the base case, but exhibit several notable differences (Figure 9a). In the absence of a carbon price, coal generation increases over time in all three models, but less so in GCAM. The reference projection for nuclear varies widely across the models: more than doubling in GCAM, decreasing in MERGE, and roughly constant in EPPA. Deployment of renewables is modest in all models, but more significant in GCAM and MERGE than in EPPA. Annual wind generation reaches the 3 EJ range by the end of the century in GCAM and MERGE but never reaches $1 \mathrm{EJ}$ in EPPA. Biomass enters the mix noticeably in GCAM and MERGE but is used at negligible levels in EPPA. Coal retains the largest electricity generation share in all three models, but GCAM and MERGE demonstrate a greater tendency to diversify the generation portfolio in the absence of a carbon policy.

Figure 9) Electricity generation by technology: a) baseline scenario; b) quadratic tax ramp; c) 2050 tax shock.

Electricity generation evolves very differently across the models when subjected to a carbon price. Under the quadratic ramp scenario (Figure 9b), total electricity generation in GCAM is $20 \%$ higher at the end of the century than in the baseline. This is in part due to an increase in electrified transportation, but IAM Comparison - 19 
also due to additional baseload generation required for carbon storage activities. In contrast, total generation drops slightly in MERGE and dramatically in EPPA.

Coal's share of electricity generation begins to decline in GCAM in 2030 and is replaced largely by nuclear and coal with CCS. GCAM deploys a diverse mix of low-carbon technologies that includes notable contributions from bioenergy with CCS, gas with CCS, wind, and solar, and is the only model to deploy solar electricity in any of our scenarios. This is in part due to GCAM's expectation of solar market maturity, the model's logit framework which gives every technology a share (no matter how small), and technology-rich bottom-up modes for solar including rooftop photovoltaic (PV), commercial scale central PV, concentrating solar power, and off-peak grid storage (generated by solar). MERGE and EPPA, on the other hand, don't incorporate demand-side additions such as rooftop PV and are also based on a least-cost assessment which can exclude technologies entirely.

MERGE projects that coal generation will increase until 2040, and then steadily decline. The model turns to nuclear, wind, coal with CCS, and a substantial amount of bioenergy with CCS as the tax ramps escalate. EPPA, in comparison, features a very rigid electricity sector. Generation shares barely change until 2070 when the tax exceeds $\$ 100 / \mathrm{tCO}_{2}$. In the last several periods, the system response is essentially limited to coal with CCS replacing conventional coal. Unlike the other models that exhibit significant changes in the electricity sector as the quadratic tax increases, EPPA reacts primarily by reducing total generation relative to the baseline. The generation portfolio is altered only when the tax is very high.

When exposed to a tax shock (Figure 9c), GCAM and MERGE approach roughly the same mix at the end of the century as the respective ramp scenarios, but the paths they take to get there are quite different. When the shock activates, GCAM changes completely in just one period as total generation increases by $30 \%$, coal generation drops from $10 \mathrm{EJ}$ to virtually zero, and a diverse mix of bioenergy with CCS, gas with CCS, coal with CCS, solar, wind, and nuclear takes over the electricity portfolio. The results are particularly striking in that the CCS technologies, which are not in use in 2045, collectively IAM Comparison - 20 
produce $12 \mathrm{EJ}$ (37\%) of electricity generation in the first year of the tax shock. Given that new technologies tend to penetrate markets gradually, the feasibility of this dramatic initial deployment of CCS technologies is suspect. In contrast, MERGE begins preparing for the tax shock several decades in advance and eventually arrives at a similar mix since the tax shock and the ramp scenario ultimately reach the same future tax value of $\$ 200 / \mathrm{tCO}_{2}$. The difference under the shock is that the bulk of the conversion begins earlier and bioenergy with CCS contributes more relative to coal with CCS in the period when the tax shock is introduced.

The rigidity of the EPPA electricity sector is most apparent in the 2050 tax shock scenario. Its immediate reaction to the shock is to reduce total generation and increase the nuclear and gas shares to allow coal generation to decline gradually over two decades. Coal with CCS eventually enters the mix then quickly becomes the single dominant generation technology by the end of the century. Although EPPA is a simulation model and the carbon price is constant from 2050 onward, the system continues to change throughout the entire run duration. That it takes several decades after the shock for coal with CCS to generate considerable electricity is evidence that constraints on adoption significantly limit the ability of the EPPA electricity sector to swiftly adapt to a new carbon policy.

We can quantify the extent of the structural impacts to the electricity sector with the Transformation Indicator. The base year is 2010, so all TI profiles begin at 0 in 2010 and evolve over time. Higher TI values indicate a larger structural change in the electricity generation portfolio from the base year. All models alter the fuel mix under a policy so the TI for each changes over the century (Figure 10a). As the ramp scenarios proceed, GCAM and MERGE continue to shift their respective electricity sectors until they exhaust technology options in the later years. With the shock scenario, MERGE anticipates the policy while GCAM waits for implementation before reacting. The incremental TI shows the transformation from period to period (Figure 10b), which highlights the dramatic transformation in GCAM, in which very little additional change takes place once the initial transformation is complete.

IAM Comparison -21 
Figure 10) Transformation Indicator (TI) and Incremental TI.

The EPPA transformations are a little less intuitive. In the baseline, coal accumulates an increasing fraction of the electricity sector, which defines the increasing TI. With the introduction of a ramp policy, EPPA predicts a reduction in energy demand. This leads to less expansion of coal-fired electricity, which in turn reduces the amount of transformation the electricity sector experiences. As the price exceeds $\$ 100 / \mathrm{tCO}_{2}$, EPPA finally makes significant changes to the sector and TI radically increases in the last few decades. Similarly, the shock scenario shows an immediate reduction in energy demand that has the short term effect of lowering the TI for a few periods. However, the shock eventually requires EPPA to deploy low-carbon alternatives which significantly alter the fuel mix. This is further evidence that EPPA is less optimistic about low-carbon technology substitution possibilities than the other models.

\section{Discussion}

We compared model results from three Integrated Assessment Models (IAMs) to show that the implications of a global carbon tax on the U.S. energy system depend on the particular IAM used. All three models agree that if a tax ramp is not agreed upon soon, a significant shock will be required within a few decades to attempt to catch up to the emissions under a ramp. Under all policy scenarios, all models assume CCS technology will be cost-effective in the long run, and rely heavily on CCS-coupled electricity generation technologies.

However, that's where the agreement ends, and all other results depend heavily on the particular model structure and assumptions. Model structure and technology representation are critical. The results show there are four important model features that drive inter-model variations in results: 1) foresight; 2) simulation vs. optimization; 3) electricity supply sector flexibility; and 4) technology representation. Consumers of IAM results should be aware of how each feature is represented in a particular model.

IAM Comparison -22 
Whether a model assumes firms and consumers have perfect foresight about future prices or believe that current prices will continue over the model's time horizon has a tremendous influence on the timing of its response to any policy. This is most apparent in the tax shock scenarios. Myopic models wait until the shock is introduced, then react quickly and sometimes dramatically. Models with perfect foresight will anticipate all future market conditions and policies and begin adapting decades in advance, enabling a gradual transition to a new energy mix. This may be reasonable if the anticipated policy is imminent. However, if the policy is introduced well into the future, perfect foresight will overstate the degree of forward thinking that characterizes energy sector decision makers; policies that will not be implemented for many years lack credibility for many reasons, not least of which is that the policy makers will probably be different people by that time. So, for long-range policies, configuring the model to solve using the model baseline parameters until the time at which the future policy is implemented would be far more useful.

The implications of using a simulation or optimization model go beyond the foresight issue. Essentially, an optimization model addresses the prescriptive question of the best possible policy, while a simulation model addresses the descriptive question of what would happen if a particular policy is implemented. An optimization model will solve for the least-cost implementation pathway. Yet, the leastcost solution, by definition, will underestimate real costs since actual policy implementation will most certainly not be perfect. Knowing the solver structure will help a user determine whether the model is appropriate for the question at hand and interpret the results properly.

The models in this study exhibit large variation in electricity supply system ability to swiftly and dramatically alter the generation mix to adapt to policy changes. The differences between GCAM and EPPA under the tax shocks illustrate this point. The GCAM electricity sector undergoes a complete revolution in just one period following a tax shock. As a result, there is an immediate decrease in CI. This GCAM behavior stands in contrast to data from historical energy transitions, in which supply-side IAM Comparison - 23 
technologies diffuse on the order of decades or even centuries (Grubler et al., 1999; Wilson, 2012). Yet, the historical record does not include the sudden implementation of a significant carbon price. On the other hand, Wilkerson (2014) showed that even a small carbon tax, as low as $\$ 15 / \mathrm{tCO}_{2}$, can drive immediate and dramatic fuel switching activity in the U.S. electricity sector, since this supply sector is the most flexible in terms of carbon intensity options. Wilkerson illustrated that almost all of the avoided carbon emissions occurs within the first few years of the implementat3ion of a carbon tax policy and over $90 \%$ of that is from the electricity sector. So the five-year, single time step, GCAM response, with its energy end-use characterization in supply and demand sectors, is, perhaps, not too extreme.

The EPPA electricity sector is comparatively rigid and takes several decades following a tax shock to evolve toward a portfolio noticeably different from the pre-shock mix. Inter-model variability in electricity supply system flexibility can be attributed to constraints models apply to control the rate of energy system evolution. For example, EPPA has a rigid electricity sector because capital stock turnover is modeled in considerable detail and the adoption of advanced low-carbon technologies requires an initially scarce fixed-factor input representing knowledge and engineering capacity. Model users should be aware of such constraints (or lack thereof) and interpret model projections of the future technology portfolio with them in mind. Awareness of the presence and parameterization of these constraints becomes increasingly crucial when considering scenarios that feature rapidly changing or dramatic environmental policies, such as our tax shocks. Ultimately, the model user must assess the validity of the results using personal judgment about plausible technology transitions.

Scenario results are strongly influenced by the set of technologies represented. Each model exhibits varying levels of bottom-up detail and allocates energy capacity differently, so the results include nonidentical sets of energy technologies. GCAM features the most technology detail, followed by MERGE and then by EPPA. It is thus not surprising that GCAM responds to a carbon tax with a more diverse set of technologies than MERGE, and both show a more varied mix than EPPA. This result is consistent with

IAM Comparison - 24 


\section{Conclusions and Policy Implications}

IAMs extrapolate conceptual and empirical market behavior, and do not project supplies, demands, and prices with separate forecasting equations. Quantities and prices for energy products and resources are set based on historical relationships (i.e., dependencies) between product supplies and demands and prices, economic activity, technological change (with economic growth and technological change projections often chosen exogenously), with a search for equilibrium prices that balance supplies and demands being the operational conceptual paradigm. This type of model is well suited to estimate long term policy impacts on energy and climate, provided one understands the equilibrium assumptions made in the model that produced the results. With long time steps and coarse market details, they are not intended for short run dis-equilibrium forecasting. IAM Comparison - 25 
The major source of inter-model variability in this study is CI. Models which include many lowcarbon technology options and weak constraints on adoption (e.g., GCAM) will react flexibly in response to a carbon price, substituting technologies quickly and dramatically to reduce $\mathrm{CI}$ and emissions. Other models with fewer low-carbon alternatives and stronger constraints on adoption (e.g., EPPA) are comparatively rigid, and the energy structure will transform less significantly and more gradually. Neither is likely 'correct' but together they bound the possible solutions. The outlook for particular technologies is highly sensitive to the IAM used. Each model has different assumptions about technology costs, performance, and availability.

Ultimately, the value of the results is in the insights gained from understanding the model's framework, inputs, and assumptions. Before using a model or published model results for policy analysis, the policymaker must know if the model is designed to answer the policy question at hand. A natural first question is to determine whether the question is prescriptive or descriptive. The former suggests using an optimization model which will recommend a set of actions, while the latter suggests using a simulation model which will evaluate the effects of a particular policy. Other characteristics to consider include scope, aggregation, economic structure, time step, and solution time horizon. Beyond that, the policymaker must also determine if the model includes the right diversity of technologies and learn what constraints are imposed on the adoption of those technologies.

A general guide to model selection and interpretation for the policymaker or other consumer of model results is summarized in Table 4. The left margin highlights two key concerns: policy stringency and timing. The columns represent what the user should look for in models to meet those concerns and what defines the critical features of such a model.

Table 4) Model recommendations and critical features to be aware of when choosing a model or interpreting results. IAM Comparison - 26 


\section{Acknowledgements}

Primary funding for this project came from the Department of Energy, Office of Science PIAMDDI grant (DE-SC005171) to the Energy Modeling Forum at Stanford University. The authors thank Jon Koomey of Stanford University and Alan Sanstad of Lawrence Berkeley National Lab for their comments on an early draft of this paper. In addition, we are grateful to anonymous reviewers for their extensive and helpful feedback. Any remaining errors — and all opinions expressed — are the responsibility of the authors.

\section{References}

IAM Comparison - 27 
Blanford, G., Merrick, J., Richels, R., Rose, S., 2013. Trade-offs between mitigation costs and temperature change. Climatic Change 123, 527-541.

Böhringer, C., Rutherford, T.F., Balistreri, E.J., Weyant, J., 2012. Introduction to the EMF 29 special issue on the role of border carbon adjustment in unilateral climate policy. Energy Economics 34, S95-S96.

Bosetti, V., Paltsev, S., Reilly, J., Carraro, C., 2012. Emissions Pricing to Stabilize Global Climate. MIT Joint Program Report Series 211.

Clarke, L., Böhringer, C., Rutherford, T.F., 2009. International, U.S. and E.U. Climate Change Control Scenarios: Results from EMF 22. Energy Economics 31, S63-S306.

Clarke, L., Krey, V., Weyant, J., Chaturvedi, V., 2012. Regional energy system variation in global models: Results from the Asian Modeling Exercise scenarios. Energy Economics 34, S293-S305.

Dimaranan, B., McDougall, R., 2002. Global Trade, Assistance, and Production: The GTAP 5 Data Base. Center for Global Trade Analysis, Purdue University.

Edmonds, J., Wise, M., Pitcher, H., Richels, R., Wigley, T., MacCracken, C., 1997. An Integrated Assessment of Climate Change and the Accelerated Introduction of Advanced Energy Technologies - An Application of MiniCAM. Mitigation and Adaptation Strategies for Global Change 1, 311-339.

Edmonds, J.A., Reily, J.M., 1986. User's guide to the IEA/ORAU Long-Term Global Energy Economic Model with Carbon Dioxide Emissions: Personal Computer Version A84PC. Institute for Energy Analysis, Oak Ridge Associated Universities, Washington DC.

EIA, 2012. Annual EnergyOutlook (AEO) 2012 With Projections to 2035 U.S. Department of Energy, Energy Information Adminsitration, Washington, D.C.

EMF, 2004. EMF 19: Alternative Technology Strategies for Climate Change Policy. Energy Economics, Special Issue Special Is, 501-755.

EMF, 2011. Energy Efficiency and Climate Change Mitigation. Stanford, CA.

Fawcett, A. a., Calvin, K. V., de la Chesnaye, F.C., Reilly, J.M., Weyant, J.P., 2009. Overview of EMF 22 U.S. transition scenarios. Energy Economics 31, S198-S211.

Fawcett, A.A., Clarke, L.E., Rausch, S., Weyant, J.P., 2014. Overview of EMF 24 Policy Scenarios. The Energy Journal 35, 33-60.

Goodess, C.M., Hanson, C., Hulme, M., Osborn, T.J., 2003. Representing Climate and Extreme Weather Events in Integrated Assessment Models: A Review of Existing Methods and Options for Development. Integrated Assessment 4, 145-171.

Goulder, L.H., 2013. Climate change policy's interactions with the tax system. Energy Economics 40, S3-S11.

IAM Comparison - 28 
Grubler, A., Nakićenović, N., Victor, D.G., 1999. Dynamics of energy technologies and global change. Energy Policy 27, 247-280.

Hummel, H., Weyant, J., 2006. Interpreting Global Energy and mission Scenarios: Methods for Understanding and Communicating Policy Insights. IPER (Interdisciplinary Progr. Environ. Resour.

Huntington, H., Weyant, J.P., Sweeney, J., 1982. Modeling for insights, not numbers: The experiences of the Energy Modeling Forum. Omega, The International Journal of Management Science 10, 449462.

IWG, 2010. Technical Support Document: Social Cost of Carbon for Regulatory Impact Analysis. Washington, D.C.

Kaya, Y., 1990. Impact of Carbon Dioxide Emission Control on GNP Growth: Interpretation of Proposed Scenarios Paper presented to the IPCC Energy and Industry Su.

Kim, S.H., Edmonds, J., Lurz, J., Smith, S.J., Wise, M., 2006. The ObjECTS Framework for Integrated Assessment: Hybrid Modeling of Transportation. Energy Journal 27, 63-91.

Knopf, B., Luderer, G., Edenhofer, O., 2011. Exploring the feasibility of low stabilization targets. Wiley Interdisciplinary Reviews: Climate Change 2, 617-626.

Krey, V., Luderer, G., Clarke, L., Kriegler, E., 2013. Getting from here to there - energy technology transformation pathways in the EMF27 scenarios. Climatic Change 123, 369-382.

Kriegler, E., 2013. Overview of the AMPERE project [WWW Document]. AMPERE Stakehold. Work. URL http://ampere-project.eu/web/images/Stakeholder_Workshop/ampere_overview_kriegler.pdf

Kriegler, E., Petermann, N., Krey, V., Schwanitz, V.J., Luderer, G., Ashina, S., Bosetti, V., Eom, J., Kitous, A., Méjean, A., Paroussos, L., Sano, F., Turton, H., Wilson, C., Vuuren, D.P. Van, 2014. Diagnostic indicators for integrated assessment models of climate policy. Technological Forecasting $\&$ Social Change (In Press).

Kriegler, E., Riahi, K., Petermann, N., Bosetti, V., Capros, P., Vuuren, D.P. van, Criqui, P., Egenhofer, C., Fragkos, P., Johnson, N., Paroussos, L., Behrens, A., Edenhofer, O., The AMPERE Consortium, 2014. Assessing Pathways toward Ambitious Climate Targets at the Global and European Levels: A synthesis of results from the AMPERE project [WWW Document]. URL http://ampereproject.eu/web/images/Final_Conference/ampere_synthesis_5-2014-compact.pdf

Manne, A., Mendelsohn, R., Richels, R., 1995. MERGE A model for evaluating regional and global effects of. Energy Policy 23, 17-34.

Manne, A.S., Richels, R.G., 1992. Buying greenhouse insurance : the economic costs of carbon dioxide emission limits. MIT Press, Cambridge, MA.

Nakicenovic, N., Alcamo, J., Davis, G., de Vries, B., Fenhann, J., Gaffin, S., Gregory, K., Grübler, A., Jung, T., Kram, T., La Rovere, E., Michaelis, L., Mori, S., Morita, T., Pepper, W., Pitcher, H., Price, L., Riahi, K., Roehrl, A., Rogner, H.-H., Sankovski, A., Schlesinger, M., Shukla, P., Smith, S., IAM Comparison - 29 
Swart, R., van Rooijen, S., Victor, N., Dadi, Z., 2000. IPCC Special Report on Emissions Scenarios. Cambridge University Press.

NBER, 2013. National Income and Product Accounts Tables [WWW Document]. Table 1.1.9. Implicit Price Deflators Gross Domest. Prod. URL http://www.bea.gov/iTable/index_nipa.cfm

Nordhaus, W.D., 1992. Rolling the "DICE":An optimal transition path for controlling green house gases. Resource and Energy Economics 15, 27-50.

Nordhaus, W.D., 1993. Optimal Greenhouse-Gas Reductions and Tax Policy in the "DICE" Model. The American Economic Review 83, 313-317.

Paltsev, S., Reilly, J., Jacoby, H., Eckaus, R., McFarland, J., Sarofim, M., Asadoorian, M., Babiker, M., 2005. The MIT Emissions Predication and Policy Analysis (EPPA) Model: Version 4, MIT Joint Program on the Science and Policy of Global Change, Report. MIT.

Pindyck, R.S., 2013. Climate Change Policy: What Do the Models Tell Us? Journal of Economic Literature 51, 860-872.

Schneider, S., Lane, J., 2005. Integrated Assessment Modeling of Global Climate Change: Much Has Been Learned-Still a Long and Bumpy Road Ahead. Integrated Assessment Journal 5, 41-75.

Schneider, S.H., 1997. Integrated assessment modeling of global climate change: Transparent rational tool for policy making or opaque screen hiding value-laden assumptions? Environmental Modeling and Assessment 2, 229-249.

Stanton, E. a., Ackerman, F., Kartha, S., 2009. Inside the integrated assessment models: Four issues in climate economics. Climate and Development 1, 166.

Stern, N., 2013. The Structure of Economic Modeling of the Potential Impacts of Climate Change: Grafting Gross Underestimation of Risk onto Already Narrow Science Models. Journal of Economic Literature 51, 838-859.

Weyant, J., Knopf, B., De Cian, E., Keppo, I., van Vuuren, D.P., 2013. Introduction To the Emf28 Study on Scenarios for Transforming the European Energy System. Climate Change Economics 04, 1302001.

Weyant, J., Kriegler, E., 2014. Preface and introduction to EMF 27. Climatic Change 123, 345-352.

Weyant, J.P., de la Chesnaye, F.C., Blanford, G.J., 2006. Overview of EMF-21: Multigas Mitigation and Climate Policy. Energy Journal 27, 1-32.

Wigley, T.M.L., 2008. MAGICC/SCENGEN 5.3: USER MANUAL (version 2) [WWW Document]. URL http://www.cgd.ucar.edu/cas/wigley/magicc/UserMan5.3.v2.pdf

Wilkerson, J.T., 2014. Economic and Distributional Impacts from Carbon Fee and Dividend Policies (Doctoral Thesis, Stanford University) [WWW Document]. URL http://searchworks.stanford.edu/view/10530922

IAM Comparison - 30 
Wilkerson, J.T., Cullenward, D.J., Davidian, D., 2013. End Use Technology Choice in the National Energy Modeling System (NEMS): An Analysis of the Residential and Commercial Buildings Sectors. Energy Economics -In Press.

Wilson, C., 2012. Up-scaling, formative phases, and learning in the historical diffusion of energy technologies. Energy Policy 50, 81-94.

Wise, M., Calvin, K., Thomson, A., Clarke, L., Bond-Lamberty, B., Sands, R., Smith, S.J., Janetos, A., Edmonds, J., 2009. Implications of limiting CO2 concentrations for land use and energy. Science $324,1183-6$. 


\section{Comparison of Integrated Assessment Models: Carbon Price Impacts on U.S. Energy}

Jordan T. Wilkerson, Benjamin D. Leibowicz, Delavane D. Turner, John P. Weyant

Table 1) Model comparison summary.

\begin{tabular}{|c|c|c|c|}
\hline & GCAM & MERGE & EPPA \\
\hline Organization & PNNL/JGCRI & EPRI & MIT \\
\hline $\begin{array}{r}\text { Programming } \\
\text { Environment }\end{array}$ & $\mathrm{C}^{++}$ & GAMS & GAMS \\
\hline Scope & Global & Global & Global \\
\hline Emphasis & $\begin{array}{l}\text { Energy and Land } \\
\text { Use }\end{array}$ & $\begin{array}{l}\text { Investment and } \\
\text { Economic Growth }\end{array}$ & $\begin{array}{l}\text { Energy-Economy } \\
\text { Interactions }\end{array}$ \\
\hline Aggregation & $\begin{array}{l}15 \text { Socioeconomic } \\
\text { regions } \\
172 \text { Land use } \\
\text { regions }\end{array}$ & 9 Regions & 16 Regions \\
\hline $\begin{array}{r}\text { Economic } \\
\text { Structure }\end{array}$ & Partial Equilibrium & $\begin{array}{c}\text { General } \\
\text { Equilibrium }\end{array}$ & $\begin{array}{c}\text { General } \\
\text { Equilibrium }\end{array}$ \\
\hline $\begin{array}{r}\text { Optimization } \\
\text { Structure } \\
\end{array}$ & Simulation & $\begin{array}{l}\text { Inter-temporal } \\
\text { Optimization } \\
\end{array}$ & Simulation \\
\hline Time Steps & 5-year & 10-year & 5-year \\
\hline $\begin{array}{r}\text { Solution Date } \\
\text { Range }\end{array}$ & $1990-2095$ & $2000-2100$ & $1997-2100$ \\
\hline
\end{tabular}


Table 2) Regions in each model, roughly lined up with similar regions in other models

\begin{tabular}{c|c|c}
\multicolumn{2}{c}{ Regions of the World } \\
\hline GCAM (14 Regions) & MERGE (9 Regions) & EPPA (16 Regions) \\
\hline United States & United States & United States \\
Canada & Canada \\
Australia \& New Zealand & Canada-Australia-New Zealand & Australia \& New Zealand \\
Western Europe & & European Union \\
Eastern Europe & Greater European Union & Eastern Europe \\
Former Soviet Union & Russia & Former Soviet Union \\
India & India & India \\
Japan & Japan & Japan \\
China & China \\
China \& Centrally-planned Asia & Rest of Asia & Indonesia \\
South \& East Asia & & Higher Income East Asia \\
Korea & & Mexico \\
& & Middle East \\
Middle East & & Africa \\
Africa & & Latin America \\
Latin America & Rest of World \\
\hline
\end{tabular}


Table 3) Electricity generation technologies in each model.

\section{Electricity Generation Technologies}

\begin{tabular}{c|c|c}
\hline \multicolumn{1}{c|}{ GCAM (16) } & MERGE(12) & EPPA (10) \\
\hline \hline Coal & Coal & Coal \\
Coal-CCS & Coal-CCS & Coal-CCS \\
Natural Gas & Natural Gas & Natural Gas \\
Natural Gas-CCS & Natural Gas-CCS & Oil \\
Oil & Oil & Nuclear \\
Oil-CCS & Nuclear & Nuclear-Advanced \\
Nuclear & Biomass \\
Biomass & Biomass & Hydro \\
Biomass-CCS & Biomass-CCS & \\
Hydro & Hydro & Solar and Wind \\
Wind & Wind & \\
Rooftop Solar & & \\
Solar (other) & & \\
\hline Geothermal & & \\
Battery & Other Renewables & \\
\hline
\end{tabular}


Table 4) Model recommendations and critical features to be aware of when interpreting results.

\begin{tabular}{|c|c|c|c|}
\hline \multicolumn{2}{|c|}{ Policy Scenario Characteristics } & \multirow[b]{2}{*}{$\begin{array}{l}\text { Model Recommendations } \\
\text { - } \quad \text { Detailed set of clean } \\
\text { technologies on supply and } \\
\text { demand sides } \\
\text { - Land use modeling if } \\
\text { bioenergy is a major policy } \\
\text { response }\end{array}$} & \multirow[b]{2}{*}{\begin{tabular}{ll} 
& \multicolumn{1}{c}{ Critical Features } \\
- & Technology-specific cost \\
reduction parameters \\
- & Share limits for intermittent \\
renewables \\
- Technology performance \\
assumptions
\end{tabular}} \\
\hline $\begin{array}{c}\text { Policy } \\
\text { Stringency }\end{array}$ & Stringent & & \\
\hline & Mild & $\begin{array}{l}\text { Baseline accurately } \\
\text { calibrated to recent data } \\
\text { - Demand-side emission } \\
\text { reduction potential }\end{array}$ & $\begin{array}{ll}\text { - } & \text { Fossil fuel resource } \\
\text { endowments and/or prices } \\
\text { - } & \text { Performance and cost } \\
& \text { parameters for CCS options }\end{array}$ \\
\hline \multirow[t]{2}{*}{ Policy Timing } & $\begin{array}{c}\text { Implemented } \\
\text { Gradually }\end{array}$ & $\begin{array}{l}\text { - Inter-temporal optimization } \\
\text { - } \quad \text { Perfect foresight (assuming } \\
\text { long-term policy would be } \\
\text { agreed upon at the start) }\end{array}$ & $\begin{array}{l}\text { Introduction dates for } \\
\text { emerging technologies } \\
\text { - Capital stock lifetimes }\end{array}$ \\
\hline & $\begin{array}{c}\text { Delayed } \\
\text { (e.g., Shock) }\end{array}$ & $\begin{array}{l}\text { - } \quad \text { Simulation } \\
\text { - No foresight or myopic } \\
\text { foresight (assuming sudden, } \\
\text { drastic policy is an } \\
\text { emergency climate measure) } \\
\text { - Technology adoption } \\
\text { constraints }\end{array}$ & $\begin{array}{l}\text { - } \text { Technology adoption } \\
\text { constraint parameterizations } \\
\text { - Handling of stranded capital } \\
\text { assets }\end{array}$ \\
\hline
\end{tabular}




\section{Comparison of Integrated Assessment Models: Carbon Price Impacts on U.S. Energy}

Jordan T. Wilkerson, Benjamin D. Leibowicz, Delavane D. Turner, John P. Weyant

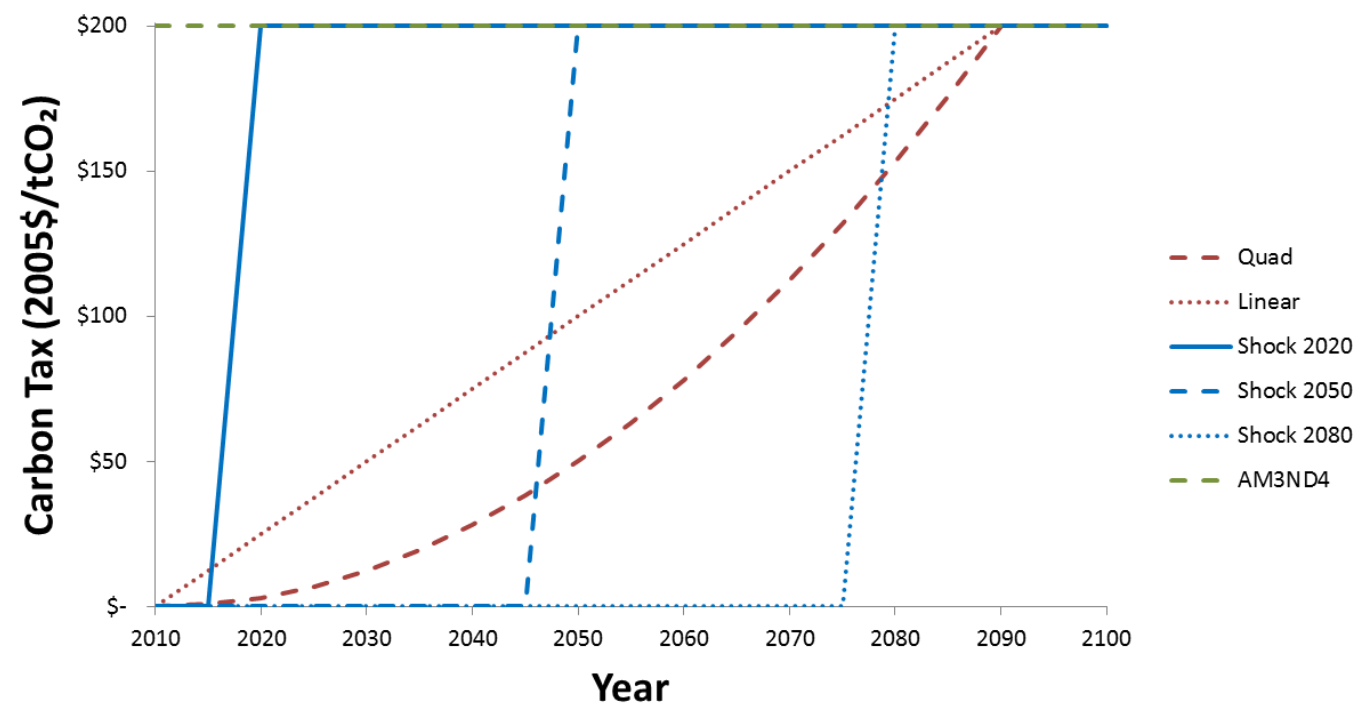

Figure 1) Carbon tax profiles applied in all scenarios. Taxes are in $2005 \$$. 

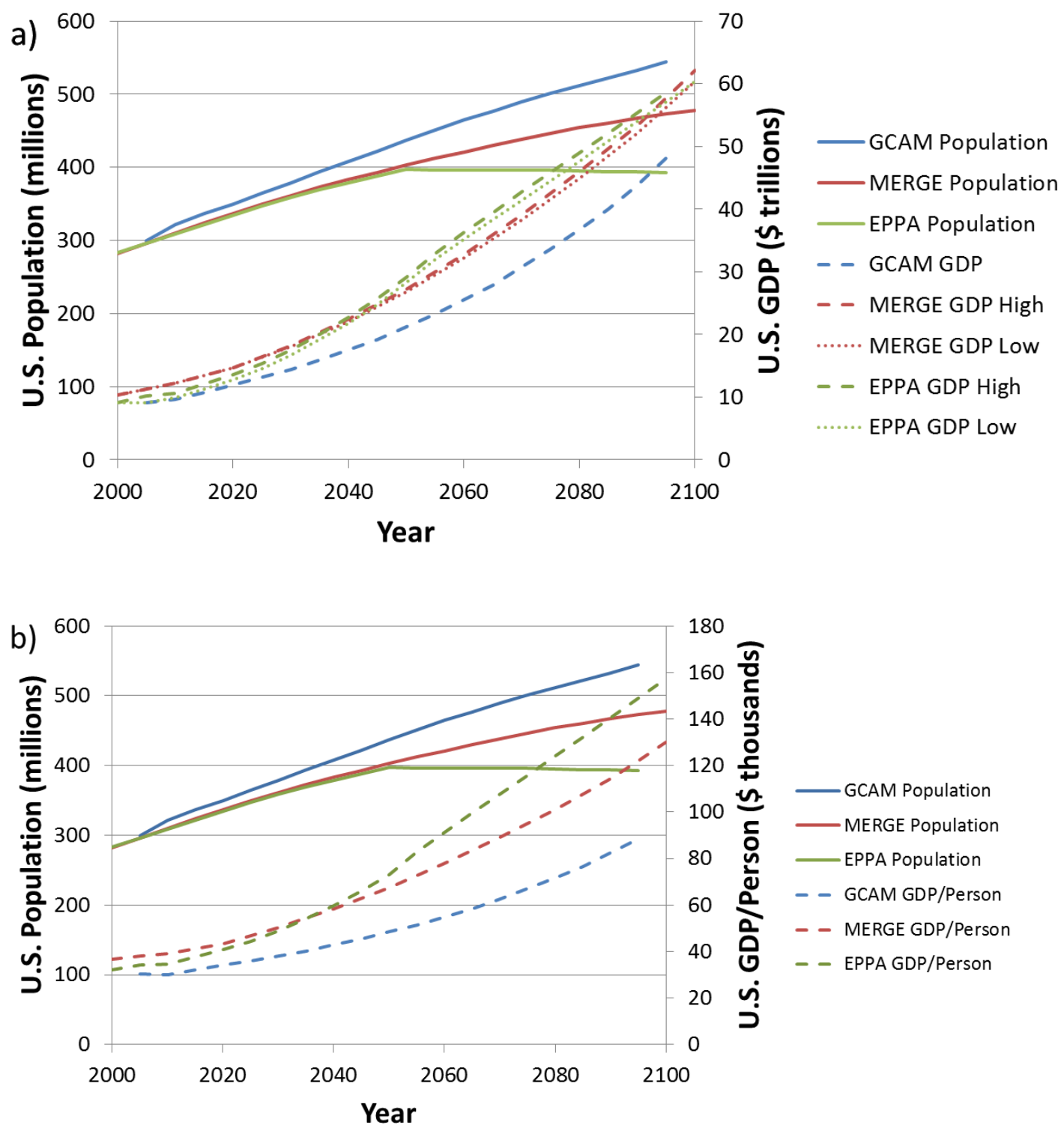

Figure 2) a) U.S. population and GDP; GDP is endogenous in MERGE and EPPA so the high and low lines establish the range from our scenarios; b) population and per capita GDP.

IAM Comparison - 1 

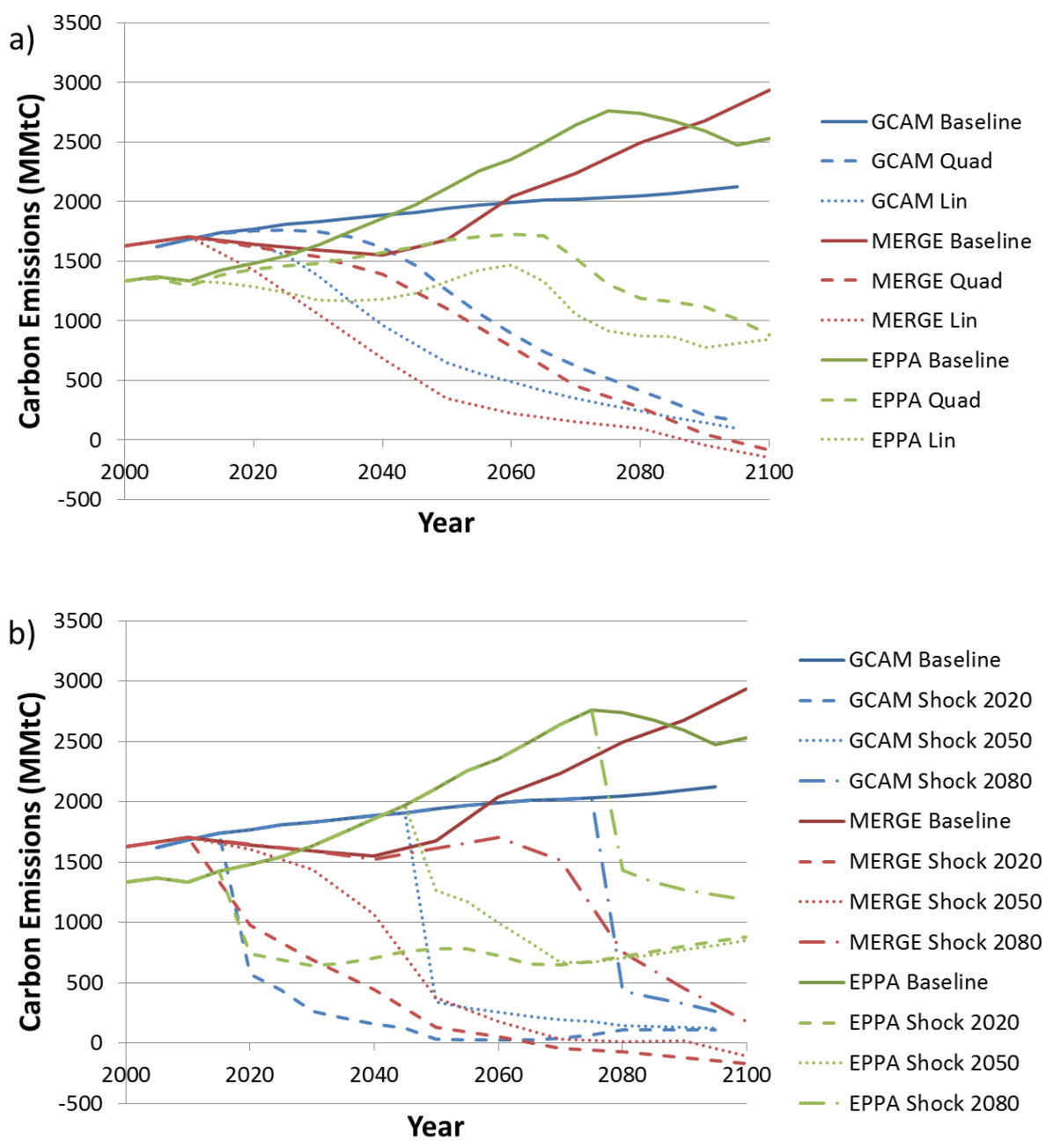

Figure 3) Carbon emissions: a) tax ramp scenarios; b) tax shock scenarios.

IAM Comparison - 2 


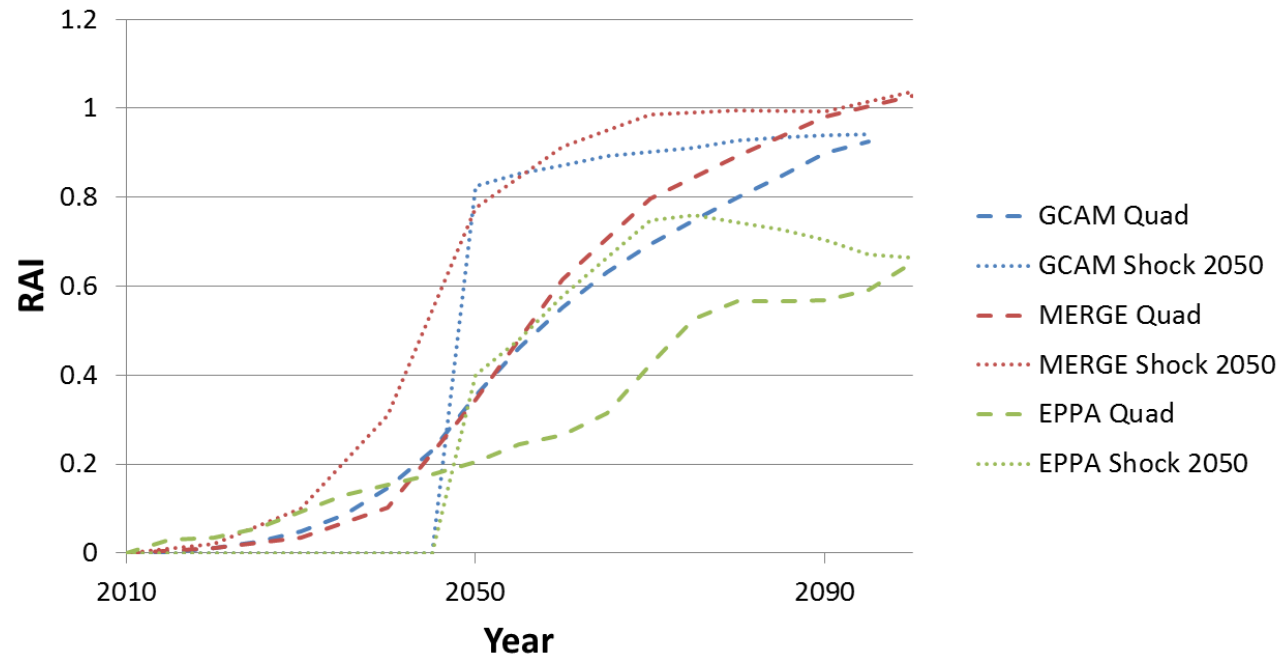

Figure 4) Relative Abatement Index (RAI) for the quadratic tax ramp and 2050 tax shock scenarios.

IAM Comparison - 3 

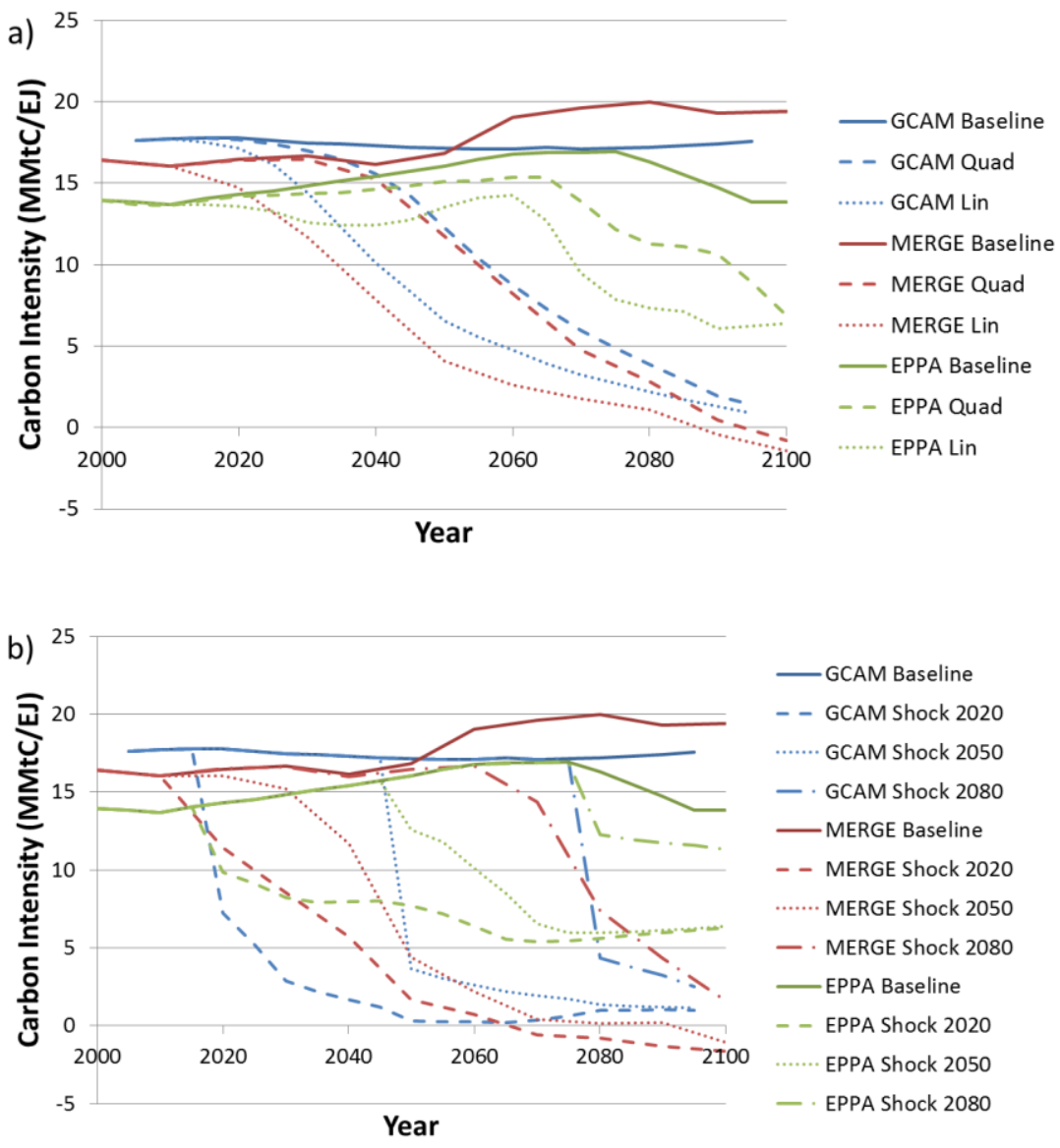

Figure 5) Carbon intensity: a) tax ramp scenarios; b) tax shock scenarios.

IAM Comparison -4 

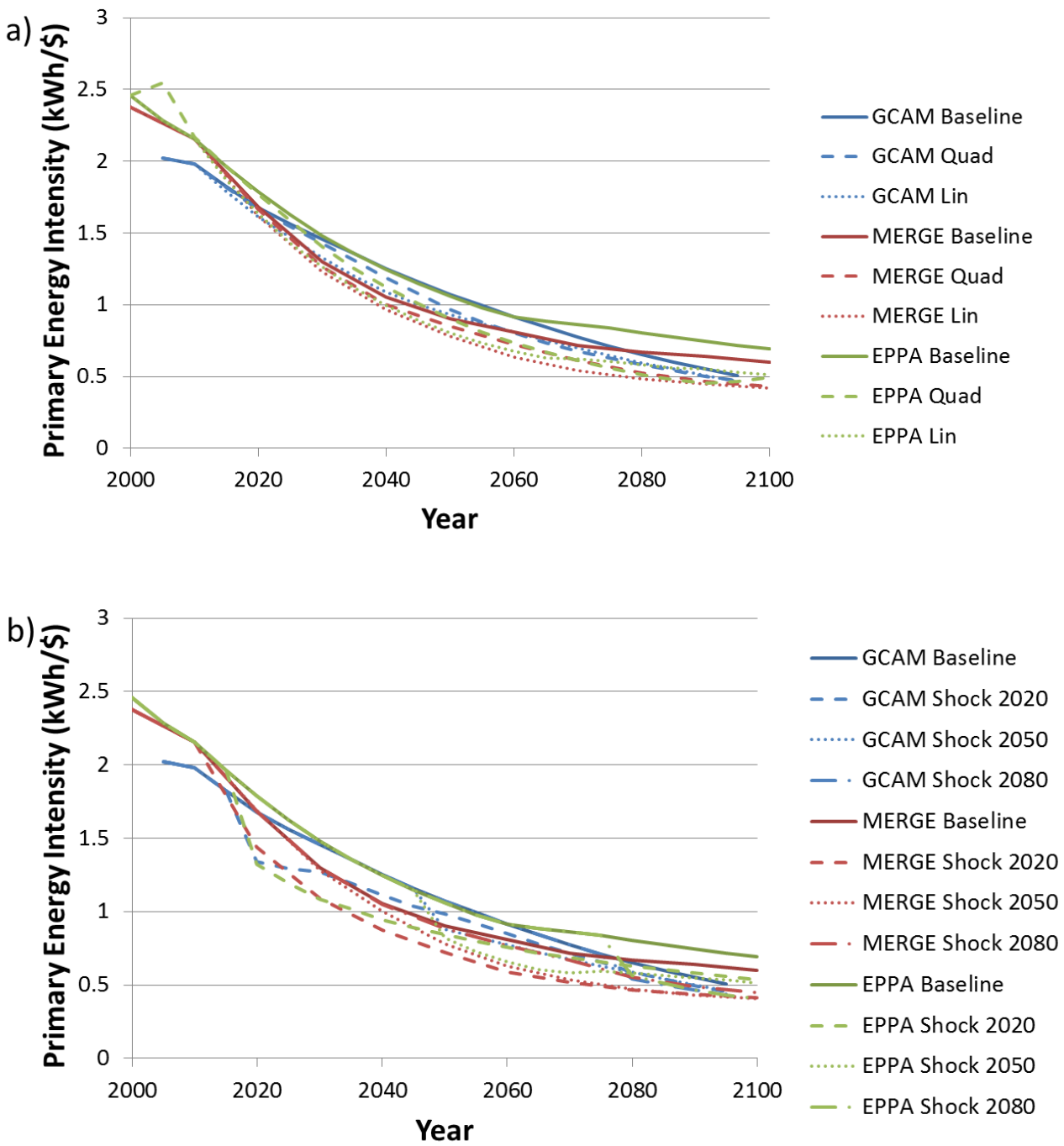

Figure 6) Primary energy intensity: a) tax ramp scenarios; b) tax shock scenarios.

IAM Comparison - 5 


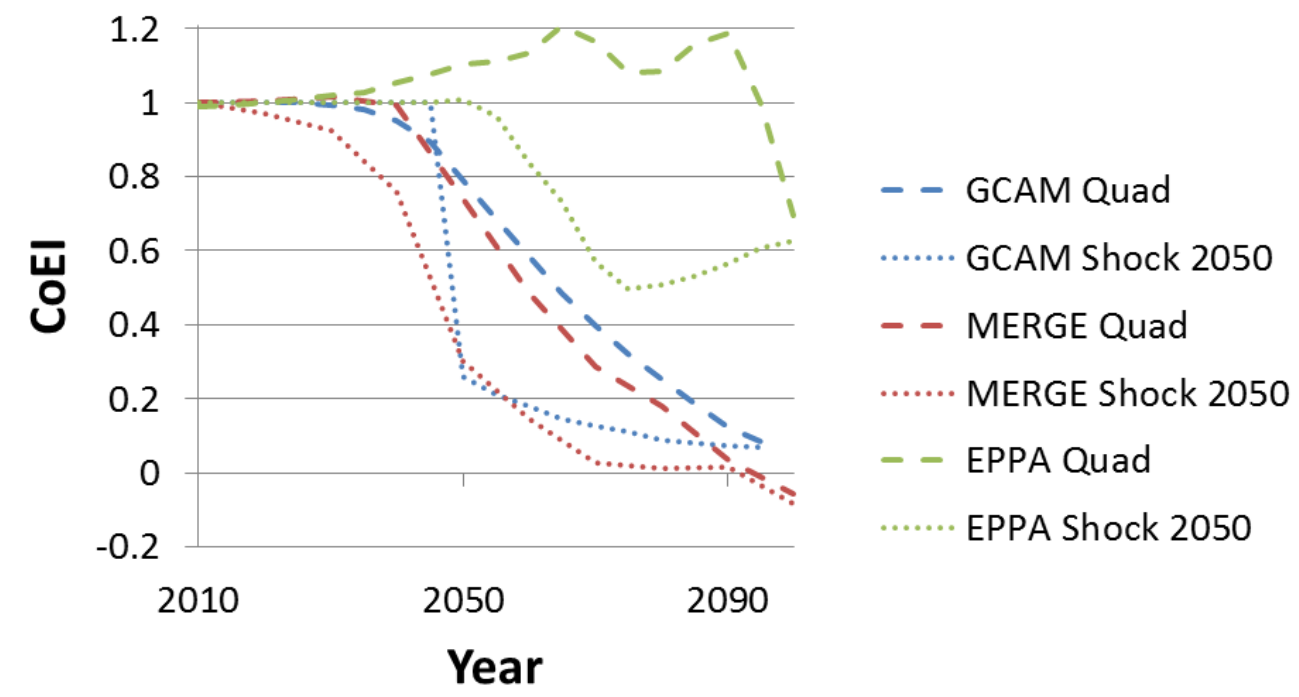

Figure 7) Carbon over Energy Intensity (CoEI) indicator for the quadratic tax ramp and 2050 tax shock scenarios.
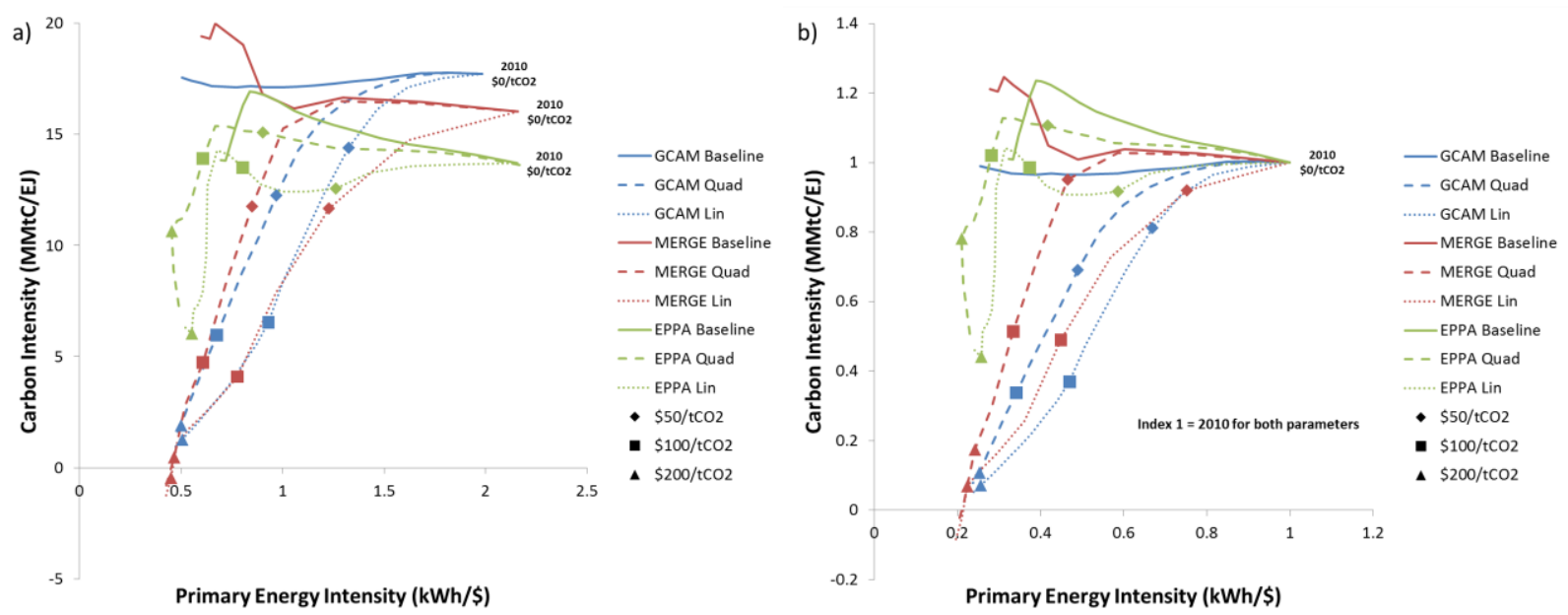

Figure 8) Evolving energy intensity and carbon intensity: a) intensities and b) indexed to 2010 value for each model. All models begin in the top right of the plots, then generally move left and down toward lower energy and carbon intensities through the model runs.

IAM Comparison -6 
a) Baseline Scenario
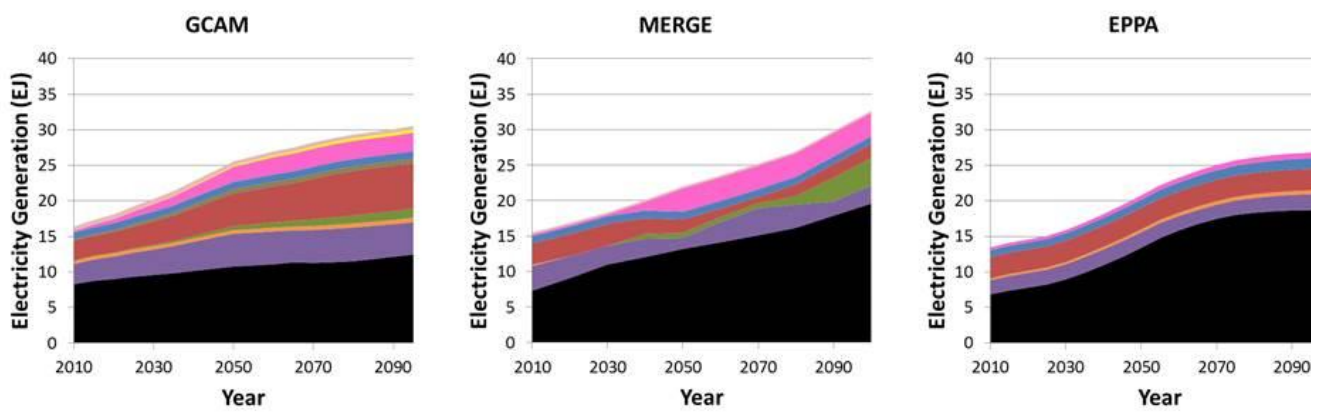

Other
Bio CCS

b) Quadratic Tax Ramp
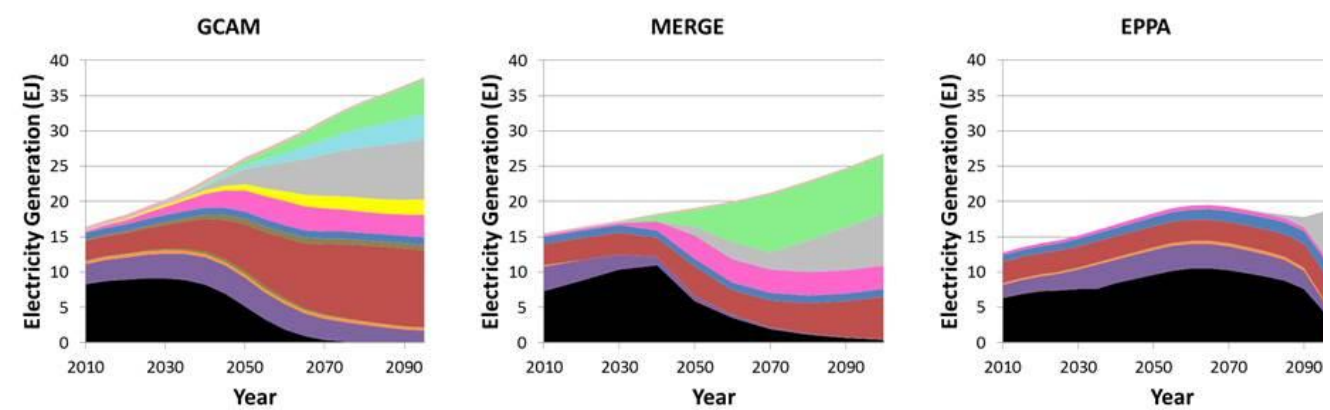

Gas CCS

Coal CCS

c) 2050 Tax Shock

GCAM
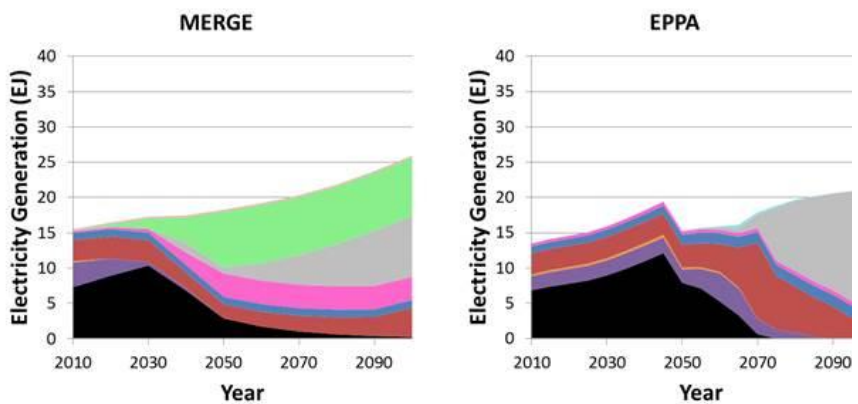

Figure 9) Electricity generation by technology: a) baseline scenario; b) quadratic tax ramp; c) 2050 tax shock. 

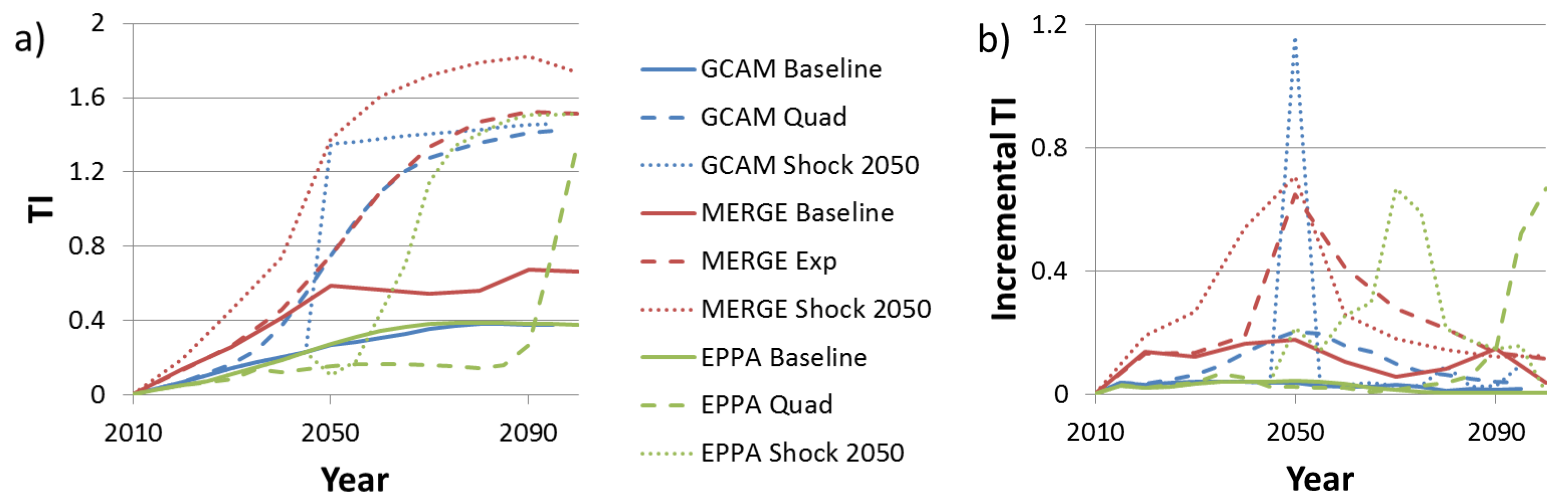

Figure 10) Transformation Indicator (TI) and Incremental TI.

IAM Comparison -8 